\title{
CORPOREIDADES CONTEMPORÂNEAS:
}

\author{
DO CORPO-IMAGEM AO CORPO-DEVIR
}

Jardel Sander ${ }^{\star}$

\section{ReSUMO}

Este trabalho procura fornecer uma perspectiva sobre o corpo em suas relações com a subjetividade, a cultura e a história. Partindo da concepção do corpo como multiplicidade-corporeidades -, podemos visualizar tanto suas inscrições históricas, quanto suas possibilidades de resistência. Para além da evidência que o corpo assumiu na contemporaneidade, buscam-se suas condições de possibilidade e seus desdobramentos. Conclui-se que a possibilidade de ruptura face às inscrições históricas - tanto a dureza do regime militar, quanto à fluidez e espetacularização contemporâneas - passa pelo resgate do movimento de invenção e criação no corpo, e a dança contemporânea pode servir como caminho possivel.

Palavras-chave: corpo; subjetividade; dança; contemporaneidade; décadas de 1970, 1980 e 1990.

\section{CONTEMPORARY BODY EXPERIENCES:}

\section{FROM BODY AS IMAGE TROUGH BODY AS DEVENIR}

\begin{abstract}
This work looks for to supply a perspective about the body and its relations to the subjectivity, culture and history. We depart from the conception of body as multiplicity - "bodyness", body experienced -, through which it is possible to visualize its historical inscriptions and its possibilities to resist, beyond contemporary obviousness body has assumed. It is concluded that the rupture to historical inscriptions - both the hardness of the Brazilian military regime, as the contemporary fluidity and spectacularization - may be made through the redemption of creation and invention movement in the body, and contemporary dance can serve as a possible way.
\end{abstract}

Keywords: body; subjectivity; dance; contemporary; 1970's, 1980's and 1990's.

\footnotetext{
^ Psicólogo. Doutor em Psicologia Clínica (Núcleo de Subjetividade) pela Pontifícia Universidade Católica de São Paulo. Atualmente é professor do curso de Psicologia da Pontifícia Universidade Católica de Minas Gerais. Endereço: Pontifícia Universidade Católica de Minas Gerais, Departamento de Psicologia. Rua Walter Ianini, 255 - São Gabriel. CEP: 31950-640 - Belo Horizonte, MG - Brasil E-mail: jardelss@gmail.com
} 
Tremes, carcaça?

Ainda tremerias mais

Se soubesses aonde te levo.

Turenne

\section{ObViedades, OU QuaSe}

Já há algum tempo que se tem falado e escrito sobre corpo. De tal maneira que poderíamos nos perguntar se há, efetivamente, algo de novo a ser dito. Afinal, parece que o corpo tem se estabelecido com tal obviedade no cenário contemporâneo que nossa tarefa seria, antes de reforçar sua evidência, a de desevidenciá-lo. Devolver-lhe alguma surpresa.

Talvez possamos fazer isso se não nos ocuparmos primeiramente em querer "definir" o que seja o corpo. Poderíamos, diversamente, mostrar o corpo enquanto uma série de práticas, isto é, como "corporeidades". Desta forma, poderíamos dar conta de sua multiplicidade irredutível. É disso que se trata neste trabalho: de um entrecruzamento de temáticas, interpenetrações, atravessamentos. $\mathrm{O}$ que se pretende aqui é tentar compreender, através de uma cartografia de processos de subjetivação na contemporaneidade, um pouco sobre o que temos vivido como "corpo". Isto será feito através de uma análise de práticas histórico-corporais no que elas apresentam de potências e despotencializações, em seus movimentos de enredamento e captura, mas também em suas linhas de fuga. Nesse trajeto, buscase afirmar o presente, não como assunção do que nos é oferecido, mas como uma procura por possíveis. É a busca por uma voz.

O que isso implica? Traçar um percurso, no que os caminhos têm de provisórios, incertos e perigosos.

No entanto, os perigos do nosso caminho não se referem ao oculto que nos arrebata; mas ao evidente que nos satura: a obviedade de que falávamos no início. Pois há um clima de evidência, nessa nossa cultura da imagem. É seu modus operandi: evidenciar, abarrotando nosso entorno com cintilantes obviedades. E não há saída fácil das obviedades, uma vez que elas nos trazem tranqüilidade e alívio.

Mas, afinal, de que obviedades se tratam? São três, interconectadas: corpo, cultura, subjetividade. Cada um desses elementos traz em si uma perigosa evidência, ou mesmo uma tendência a evidenciar-se. E as ligações entre eles parecem ainda mais evidentes. E isso é perturbador, não pelo fato em si de estarem conectados; mas pelo fato de, uma vez capturados por clichês, sustentarem as forças conservadoras. E essa parece ser a assustadora tendência das interpretações mais corriqueiras da relação corpo - cultura - subjetividade: conservação.

O paradoxo que se nos apresenta é o de subsistir, em meio ao império do efêmero (nossa assim chamada "pós-modernidade"), uma estranha conservação: uma engenhosa forma de manutenção e sustentação "através" do movimento. Pois nossa contemporaneidade nos apresenta uma pluralidade de culturas díspares e (supostamente) interconectadas. Como se a supressão espaço-temporal (via globalização) nos situasse numa grande comunidade global, tão rica quanto "conectada". 
Nesse cenário, o corpo parece servir de anteparo para múltiplas projeções da utópica aldeia global: em sua inelutável evidência, apresenta-se como signo comum da existência humana em qualquer lugar; e, de modo similar, demonstra sua inquestionável capacidade de "transformar-se".

O resultado lógico da constatação de uma pluralidade cultural em toda sua fluidez e intercambialidade, e de corpos transformáveis não poderia senão nos conduzir à - também evidente - constatação de que as subjetividades estão, por seu turno, em processos de mudança, transformando-se.

A imagem geral que emerge dessas "constatações" todas, como é próprio a um otimismo evolucionista, é que estamos seguindo o natural, embora contraditório, curso da evolução. Estamos melhorando, temos melhorado.

No entanto, e esse é o paradoxo de que falávamos acima, há estranhos movimentos de conservação que estagnam, amiúde, culturas, corpos e subjetividades. O que seriam exatamente estes movimentos? Simples e temerários anacronismos? Tentativas de sobrevivência? Sintomas de que a transformação talvez passe por outras vias que não a da obviedade evolutiva? Formas, às vezes marcadamente obsoletas e mal-sucedidas, de resistência?

Para além desta tríade de obviedades, ainda poderíamos elencar uma quarta: a de que as subjetividades são "criativas", isto é, imbuídas de criatividade, sendo que o modelo usado para isto é o da criação artística, ou seja, o fato da arte ser um espaço privilegiado de criação. Embora esta pareça ser uma característica das artes há muito tempo, em nossa contemporaneidade ela adquire uma especificidade, pois a criação tornou-se indispensável para o nosso sistema de produção, que demanda dos indivíduos justamente esse seu potencial de criar. Portanto, todo ser humano que se preze, independentemente de ser ou não "artista", deve estar de alguma forma conectado à criação, deve ser "criativo".

Já há algum tempo que a arte transbordou de seus espaços sagrados museus e galerias e se esparramou pelo cotidiano. Pelo menos desde o fim dos anos 1950, ela tem ocupado o dia-a-dia, a vida cotidiana. E essa ocupação instaurou uma estranheza em relação às vidas cotidianas, sendo a dimensão criativa das artes a marca de uma distância em relação ao estado de coisas da época. Tomese como exemplo as intervenções dos Provos, em Amsterdam, nos anos 1960 (GUARNACCIA, 2001), nas quais transparecia uma crítica política que passava primeiramente pelo questionamento aos modos de vida, os mais cotidianos, como no caso das bicicletas brancas, sem donos, e deixadas em vários pontos da cidade de Amsterdam para quem precisasse se deslocar até algum outro lugar, com a única condição de que não se apropriasse dela.

O que se caracterizará mais tarde como acontecimento relativamente novo (estabelecendo-se principalmente a partir dos anos 1980) é a instrumentalização dessa criação, tanto das artes quanto das vidas, para a produção de capital. O capitalismo contemporâneo, marcadamente financeiro, passará a se 
nutrir de criação. E as artes, muitas vezes, em vez de provocarem estranhamento, têm se assemelhado ao sistema, entrando vaidosamente e de bom grado na glamorização por ele patrocinada.

No entanto, algumas experimentações artísticas podem nos mostrar saídas, através de outras perspectivas, ou outros modos de relação entre corpo - cultura - subjetividade, na medida em que traçam rotas des-evidenciantes, isto é, põem em questão o corpo, a cultura e a subjetividade. Experimentam-nos em seu poder de contágio, no improvável e provisório de seus devires. ${ }^{1} \mathrm{Na}$ verdade, enchem-nos de plurais, trazendo à tona a multiplicidade surpreendente desses elementos e das suas misturas.

As artes do corpo, por exemplo, têm algumas vezes experimentado esse outro modo, esse algo que mina a conservação, pois fazem ver que há qualquer coisa de corrosivo nessa mistura, que há algo que nega a permanência, mas que também recusa a simples "evolução"; algo foge e faz fugir, mas que não tem direção definida nem ponto de chegada; algo que se furta às definições cabais, mas do qual não se pode negar a existência. A arte - quando exerce a sua potência de criação - nos põe frente a esse caos-composto, ou compositor: caos-germe.

É a descoberta de novos possíveis. Ou ainda, limiares. Pois as artes nos dão pistas das zonas limítrofes, das bordas. No caso das artes do corpo, elas podem indicar pontos de encontro e de desencontro entre pensamento e corpo, e dessa forma nos auxiliarem a problematizar a dimensão intensiva de nossos corpos-subjetividades. São nas práticas experimentais das artes do corpo - especialmente na dança contemporânea ${ }^{2}$ - que somos convocados a experimentar esse "atletismo afetivo" a que se referia Artaud (1993[1964], p. 129 et seq.) ao tratar do trabalho do ator.

Afinal, o que se tem feito cotidianamente com o corpo - em toda a exigência imagética que sobre ele incide - é torná-lo evidente, plenamente visível, onipresente. $\mathrm{O}$ que nos leva a perguntar: podem as práticas artísticas nos conduzir a outras corporeidades? Haveria algo nas experimentações em dança contemporânea que poderia fazer emergir um incorpóreo, isto é, o acontecimento, a partir do corpo? Poderiam ser produzidas aí linhas de fuga capazes de nos arrancar do óbvio? Ou ainda: como a dança nos auxiliaria a experimentar um corpo-sem-órgãos (DELEUZE; GUATTARI, 1996[1980]) a partir do corpo e do movimento? E como isso poderia operar uma abertura ao intempestivo na cultura, à afirmação da processualidade imanente aos corpos-subjetividades, e à acolhida ao paradoxo?

Enfim, a discussão que segue busca abordar, em linhas gerais, os processos de subjetivação na interrelação com os modos de produção das corporeidades, que na atualidade confluem para a onipresença de um corpo-imagem, mas que não deixam de se abrir para outras possibilidades, isto é, estratégias possíveis à invenção de outras corporeidades, a partir do movimento especialmente na dança, através de um corpo-devir. 


\section{Nossa HerançA}

Em sua última edição da década (26.12.1979), a revista Veja faz um balanço dos anos 1970. Na parte de "Comportamento", pode-se ler o seguinte título: "A Década de Cada Um" (1979), e o subtítulo: "Depois da Frustração dos anos 60, o homem da década de 70 tornou-se prático, cultivou o espírito e investiu no corpo. Preferiu cuidar de si mesmo". Evidenciava-se, pois, o corpo como foco da subjetividade, talvez mesmo como uma espécie de "retiro", para seres já tão acuados. Fica-se sem se saber o que é essa "frustração". Mas hoje se sabe muito bem - mais do que em 1979 - o que quer dizer esse "cuidar de si mesmo".

A partir disso, e no que se observa no decorrer da década de 1980, podemos incluir, entre os inúmeros legados dos anos $1960-70^{3}$, mais este: o corpo, que vai ser transformado em corpo-vedete, em corpo-espetáculo. Não que a contracultura dos 60-70 tenha inventado o corpo, muito menos um corpo-vedete; mas ela trouxe (ou se empenhou em trazer) à tona o corpo e suas sensações, um corpo vibrátil, "sensível", no sentindo abordado por Suely Rolnik, (2006, p. 136) em sua "cartografia da América", ao descrever o hippie-em-nós, quando fala da importância, para os hippies, da conexão com o corpo vibrátil. Mais que isso: havia toda uma busca pela intensificação da sensibilidade desse corpo, para assim "tornar seus corpos vibráteis ainda mais sensíveis às latitudes e longitudes de seus afetos" (ROLNIK, 2006, p. 139).

E o curioso disso é que o corpo sensível continuou sendo exercitado no interior da dureza do regime militar, em sua primeira fase, até o AI-5 (dezembro de 1968). A partir daí, esta experimentação não pode mais ser feita a céu aberto, pois teve que recorrer de certa forma a um exílio - espacial, mas também subjetivo. E foi como efeito desse novo panorama que surgiu a particularidade própria a duas vias de combate/contestação dessa época, que Dias (2003, p.160 et seq.) denomina como guerrilha e "desbunde". ${ }^{5} \mathrm{O}$ que se formou a partir daí foi uma nova forma de viver a corporeidade, espreitada pela dor e pela morte. Essa configuração, e uma certa incompatibilidade entre as experimentações da guerrilha (cujo foco era macropolítico, isto é., a organização molar, estratificada das relações políticas) e do "desbunde" (caracterizado pela micropolítica, ou seja, a dimensão que compreende os fluxos, os devires, as intensidades etc.) legará a nós, contemporâneos, um corpo sensível-temeroso: um misto de vibratibilidade e medo. Vejamos como.

A configuração geral é mais ou menos a seguinte: do lado do "desbunde", temos uma experimentação que se individualiza. Embora com alta potência micropolítica, não vai muito além do círculo de "iniciados", circunscrevendo-se a um grupo que é identificado pejorativamente como "malucos", hippies etc. Já do outro, o lado da guerrilha, tem-se, sob a alcunha de "subversivos" e "terroristas", a clandestinidade, o medo e as ofensivas violentas. Matar ou morrer. E o corpo, aqui, antes de ser um lócus de experimentação do sensível, é um instrumento de luta, na dureza própria que a batalha exige. Em ambas as vias, o público é um espaço inaceitável, intolerável, que deve ser desertado (caso do desbunde), ou violentamente modificado (caso da guerrilha). De forma semelhante, ambas as vias parecem se exercer na impossibilidade mesma de uma transformação macropolítica. ${ }^{6}$ 
$\mathrm{Na}$ verdade, a emergência do corpo sensível está mais ligada ao "desbunde", pois é aí que se tem o foco nas experimentações corporais, freqüentemente intensificadas pelos alucinógenos, que conduziam à abertura da "mente" (psicodelia) e à sensibilização do corpo vibrátil (um dos efeitos dos alucinógenos, associado a uma urgência e inquietação de seus usuários em reconquistar essa potência do sensível que o faz vulnerável ao outro). No entanto, este corpo vibrátil das práticas experimentais não ocupa a cena pública enquanto potência política. ${ }^{7}$ Não pode ocupá-la, pois, afinal, o enrijecimento dos militares tomou o governo, e o da "caretice" tomou as subjetividades e as ruas.

A impossibilidade de exercício político de um corpo vibrátil irá se agravar, na esteira de uma incompatibilidade entre as experimentações guerrilha-desbunde, o que se fará sentir nas décadas seguintes, mas sobretudo porque os modos de subjetivação serão confrontados a um outro modo de produção. Neste entrecruzamento de uma busca por atualização, uma mudança no sistema de produção e consumo e no endurecimento da macropolítica, o que se sente como uma espécie de efeito desta mistura é a proliferação dos medos, que irá encarnar, como uma ferida profunda, nas gerações seguintes. Primeiramente, um medo à experimentação por seu risco de dor e morte, encarnado pelas imagens dos corpos torturados e mortos dos "guerrilheiros". Em segundo lugar, um medo à experimentação e ao exercício público de formas de expressão tomado pelo pavor da falência subjetiva, encarnado nas imagens da loucura clínica, da indigência e do vício daqueles que foram muito longe em suas viagens e não conseguiram "voltar". Ou, simplesmente, em terceiro lugar, um medo a uma invisibilidade ou exclusão social, de um ser estranho, exótico e curioso, que não trabalha, que não produz e que nada faz, logo, que é irrelevante - imagens do hippie bicho-grilo.

Pois, afinal, o balanço da década de 70, no Brasil, remete-nos a uma multiplicação dos medos, utilizada como estratégia de governo, plantando nos corpos um pungente silêncio, no que se refere à política, no sentido tradicional do termo, e, paralelamente, à criação de uma fina faixa de experimentação, marginal, que era menosprezada através da alcunha de "malucos", "porra-loucas".

Nos anos 80, a política tradicional será repovoada por uma democracia muito frágil e por demais incipiente para ser "revolucionária"; e essa estreita faixa da experimentação (dos malucos, do desbunde) será investida, capturada e reciclada pelo capitalismo através da grande indústria do entretenimento (oferecendo prazer), dos produtos e serviços (oferecendo ilusão de originalidade) e da anexação da subjetividade flexível como principal peça da maquinaria da nova produção capitalista.

O resultado dessa equação é um corpo inelutavelmente lançado no campo das experimentações do sensível, mas que é ou drenado, ou quando se recusa à drenagem, "temeroso" frente ao custo das experimentações e de que as mesmas não tenham lá muita importância. Resultado: as experimentações do corpo sensível são evidentes, mas privadas, e acabam buscando e investindo meios de atualização que não sejam "políticos" (caminho barrado, marcado pela dor e desencadeador de medo). 
Com isso, o que temos, pelo menos desde os anos 80, estabelecendo-se plenamente nos anos 90, é a efígie do culto ao $\operatorname{corpo}^{8}$ e a prática da sua exposição, sem que necessariamente isso implique singularização alguma, mesmo porque a experimentação, amiúde, não oferece - não deve oferecer - riscos. Pelo contrário, nessa cartografia, as subjetividades são marcadas por um bizarro misto de transformação e conservação: transformar a própria vida é, nalguma medida, conservar-se. Em primeiro lugar, conservar um modo de vida do qual não se imagina poder se afastar, sob pena de falir subjetiva e socialmente; no limite máximo, uma obstinada corrida contra a morte física, movida pelo anseio de "seres que [querem] durar eternamente" (SANT'ANNA, 2001, p. 97). Dessa forma, o mundo e o outro não são mais vividos na sua potência de produzir diferença, pois é o medo que rege os encontros, e a morte é o inimigo comum.

Não é de se estranhar, pois, que a impressão que se tem contemporaneamente é a de que não nos é mais possível experimentar, no sentido de invenção, de criação de novos possíveis; e não de mercado, cuja lógica nos convida - paradoxalmente - a criar, mas no interior das suas trilhas, em seus caminhos conhecidos e supostamente garantidos. Há um certo clima de pavor a um desmoronamento qualquer, como se não pudéssemos mexer demais, sob pena de pôr tudo abaixo. Mas tudo o quê? Abaixo, para onde? O que tememos hoje?

Nosso temor ainda é por demais difuso para que se possa senti-lo e compreendê-lo em todas suas implicações. No entanto, é possível entender, a partir desse pavor, o porquê de todo o interesse naqueles que já desmoronaram: os loucos. Pelo que parece, tornamo-nos incapazes de ou mesmo desautorizados a - experimentar a criação de possíveis a partir da presença viva do outro no corpo, e tornar estas criações públicas, dar-lhes corpo. Precisamos, pois, daqueles que já estão lá (ou que assim cremos), como totalmente estrangeiros a nós, objeto de idealização defensiva que nos mantém ilusoriamente no mesmo lugar. Mesmo porque temos um perigoso fascínio pela desterritorialização, pois "a tomamos como uma finalidade em si mesma" (GUATTARI; ROLNIK, 2005, p. 342), e isso pode nos conduzir a um iminente desmoronamento subjetivo. E os loucos, já "desmoronados" na percepção social e na compreensão psi, parecem nos fornecer, a uma relativa, mas segura, distância, alguma proximidade com a desterritorialização, para - quem sabe - drenar daí algum potencial de criação.

De todo modo, nossa época tem um vivo interesse pela loucura clínica. Mais especificamente, pela possível criatividade que estaria apodrecendo nos porões onde a loucura soçobra, entretida com seus próprios fantasmas. E se fala-se da loucura, não é porque a problemática da invenção esteja diretamente a ela relacionada. Pois, o que se trata aqui é da desterritorialização, nosso temor em criar a partir do que pede passagem e da contemporânea impossibilidade de experimentar sem algum tipo de falência subjetiva.

Se observarmos as transformações nas subjetividades contemporâneas, aí incluídas as intervenções médico-estéticas sobre o corpo, perceberemos que nossa tendência é muito mais à reforma e à implementação do que à ruptura. Temos essa ilusão bem contemporânea de que se apertarmos bem os nós, se esticarmos 
bem a pele, se dosarmos bem a vida, a saúde, a alimentação, se trabalharmos com prazer etc., iremos perseverar, conservar-nos... mas conservar o quê? Será que ainda há vida em meio a tudo isso?

O objetivo último e bastante geral dessa conservação é, como já foi dito, negar a morte. Mas seu ímpeto primeiro é recusar o devir inevitável do corpo: perecer. Dessa forma, deseja-se apagar os sinais da passagem dos anos, da gula, do sedentarismo, dos "excessos" (de alegria, excitação, dor, tristeza, tédio...), para garantir o acesso ao prazer, ao gozo das maravilhas do mercado, infinitamente. Conservar o que, então? Conservar o corpo, a subjetividade, a vida, enfim, no rumo certo em direção a um ideal de beleza, juventude e fluidez, que seriam as garantias do prazer e da felicidade; só que esta é vivida como dever, ${ }^{9}$ e aquele, como um novo disciplinamento. ${ }^{10}$

No entanto, há outra forma de entender a conservação. Pensando em termos espinosistas, conservar assume um sentido de "perseverar na existência", como um dos aspectos do conatus (ou apetite), seu aspecto mecânico, que não pode ser dissociado de seu aspecto dinâmico (que visa a aumentar e favorecer); bem como do aspecto aparentemente dialético (opôr-se ao que se opõe, negar o que nega) (DELEUZE, 2002, p. 107). Perseverar, pois, na concepção de Espinosa (discutida por Deleuze), não significa manter um estado de coisas; mas conservar a aptidão de sermos afetados pelas forças, sem que elas nos destruam. E conservar, nessa acepção, não se refere prioritariamente a uma negação, embora a inclua; mas principalmente a uma afirmação da essência ${ }^{11}$ na existência, uma vez que o que se afirma são os aumentos de potência, em relação a um máximo e um mínimo, isto é, "as variações da potência de agir ou força da existência no interior desses limites positivos” (DELEUZE, 2002, p. 107).

Em outros termos, e consoantes a Rolnik (2006, p. 20), podemos dizer que o que se deve conservar é a "vida em seu processo infinito de diferenciação". Dessa forma, o que se tem é uma prudência, que não exclui a experimentação, portanto, a exposição às forças, mas as seleciona.

De modo semelhante, precisamos nos perguntar acerca do corpo, do que tem sido feito com ele, do que dele queremos, no sentido de aumento ou diminuição da sua potência de agir.

\section{SUJEITO, CORPO E CONTEMPORANEIDADE}

Talvez fosse mesmo necessário colocar as perguntas de uma forma muito simples, como os porquês das crianças: por que o corpo importa? Por que é bom? Por que não é? Afinal, qual o problema desse dispositivo - o corpo? ${ }^{12}$ Por que não aceitá-lo, vivê-lo e ponto?

Numa passagem d'olhos bastante rápida perceberemos que o corpo vai bem, obrigado. Aliás, nunca esteve melhor: saudável, longevo, belo, transformável e adaptável. Afirma-se corpo e corporeidade de diversas formas. Tudo vai bem. 
No entanto, esse corpo lindo, saudável e "flexível" parece ter sido desconectado da subjetividade enquanto processo. $\mathrm{Na}$ verdade, parece que foram separadas do corpo suas potências disruptivas. Como falávamos acima, herdamos efetivamente um corpo dolorido, machucado e reticente aos riscos inerentes às experimentações, ao mesmo tempo em que somos convocados a vivê-las. E vaise cobrindo e descobrindo novas-velhas fórmulas de reviver o corpo e dar-lhe mais poder, e que na verdade são, na grande maioria das vezes, coleções de quinquilharias mercadológicas, boas para consumo. Criar e vender.

Parece que estamos encurralados. A sensação, em relação a nossa cultura e época, é a de que tudo já foi tentado/feito. Uma sensação de um deserto de entulho, abarrotado, uma areia movediça cultural em que atolamos. E esperamos, aguardamos que algo aconteça, resolva-se. Mas, a despeito da nossa "esperança", algo se trama no interior mesmo do dispositivo corporal.

Pois, mesmo estando o corpo, também ele, entulhado, há algo de disruptivo no seu devir: pequenos movimentos que nos arrancam do conforto em relação a nossa carne. Porque, ao mesmo tempo em que parece haver uma necessidade de salvar o corpo, de preservá-lo da falência de uma experiência, a do humano, há também uma urgência pulsante de desinventá-lo. Mais que isso: é insustentável o estancamento dos fluxos, ainda mais no nível de excitação em que nos encontramos atualmente. O que ocorre é que esses fluxos são "drenados" pelo sistema capitalista, que ainda se aproveita, como um plus de perversidade, do medo às experimentações - nossa herança - para implementar ainda mais o circuito de produção-consumo.

Com isso, o que mais se observa é um infinito trabalho de manutenção (na mídia, por exemplo, e seu infindável receituário do bem-viver), como se fosse necessário reinventar o corpo como partícula-homem a cada momento. Ou manter algo da forma-Homem ${ }^{13}$ que garantisse a continuidade de todo o sistema.

Esta forma-Homem, delineada no século XIX, segundo Michel Foucault (1992), caracterizava-se por suas relações com a finitude (a dobra) da vida, do trabalho, da linguagem; em oposição à forma-Deus da época clássica, que se relacionava com o infinito (desdobra). A forma-Homem seria suplantada pelo super-homem, numa terminologia nietzschiana, que não mais se relacionaria com o infinito ou com a finitude, mas com um finito ilimitado, uma superdobra (DELEUZE, 2005).

No entanto, o que se observa atualmente quando focalizamos o corpo e as corporeidades, é uma busca obsessiva de sua infinitude (via medicina), mas com uma correlativa limitação por meio das técnicas do bem-viver, da saúde, e de toda uma nova disciplinarização. Além disso, de forma paralela, tem-se uma tentativa de tornar este corpo finito em ilimitado, na forma de um corpo-informação ou informático.

Mas o corpo resiste (LAPOUJADE, 2002). É ele próprio que não se deixa mais ocupar pelo humano, nega-lhe morada. O corpo rejeita a forma-Homem, que lhe quer organismo. Segundo Lapoujade (2002, p. 82), "o corpo não agüenta mais", tanto a disciplina (exterior) quanto o agente (interior): "O corpo sofre de um 'sujeito' que o age - que o organiza e subjetiva" (LAPOUJADE, 
2002, p.84-85). É por isso que o corpo se esconde na superfície, pois é onde o homem não quer encontrá-lo: a pele como contorno frágil, película sempre prestes a explodir, a não mais conter a carne convulsa. Pois há algo na carne que inviabiliza o humano, suas potências mal interpretadas, malditas. E a forma de tentar devolver o corpo à sua suposta estabilidade é, na verdade, uma tentativa de canalizar os seus fluxos para uma forma bem conhecida: o sujeito.

Mas homem e corpo não cessam de se dissolver nas experiências contemporâneas. E à dor da experimentação do desconhecido (tentativa de invenção e produção de vida pública) opõe-se o prazer do "re-conhecido". Porque, afinal, trata-se de uma circularidade de reconhecimento em que não se cessa de encontrar no corpo a reposição do "humano", naquilo que a forma-Homem tem de aprisionadora da vida (DELEUZE, 2005, p. 140).

Mas, falando assim, parece ser o corpo uma espécie de entidade. E podemos realmente pensá-lo como tal, uma vez que o Eu-cogito de outrora vem se transformado no Eu-corpo da nossa contemporaneidade. ${ }^{14}$ Daí que o corpo esteja servindo, amiúde, como territorialização, como demarcador do $\mathrm{Eu}$, numa tentativa de vincular o moribundo sujeito ao corpo, "encarnandoo" e, dessa forma, devolvendo-lhe a vida, como uma forma de ressurreição: ressuscitar o sujeito através do corpo.

De fato, esta empreitada não é de hoje, pois já há algum tempo que se vêm aproximando os termos de uma antiga dicotomia: corpo e alma. E o campo da atual neurociência tem encampado de maneira exemplar este debate, contemporaneizando-o, e sustentando uma aproximação entre corpo e mente. Embora muitos pesquisadores dessa área busquem nesta aproximação uma sustentação científica que favoreça à ampliação da subjetividade-corpo (abrindo-a às processualidades, à experimentação, ao intensivo), ${ }^{15}$ vislumbra-se, amiúde, nesta empreitada uma perigosa equação: o sujeito moderno, na contemporaneidade, encontra seu lugar no corpo. Podemos mesmo afirmar que é esta uma tendência nas neurociências, há pelo menos uma década.

Tome-se como exemplo paradigmático o bem conhecido O Erro de Descartes, de Antonio Damasio (1996) (primeira edição em inglês de 1994), cuja crítica ao filósofo do cogito centra-se na importância das emoções no próprio funcionamento da razão, e tendo como suporte o corpo, mais especificamente, o cérebro. Não se deve desconhecer a importância da empreitada de Damasio, no sentido de se contrapor à compartimentação do ser humano, bem como na tentativa de estabelecer uma outra qualidade da relação mente-corpo, para além do dualismo cartesiano. No entanto, essa nova relação mente-corpo, que não seria mais dualista, dá-se através de uma reelaboração da idéia de organismo. O que gera um incômodo bastante sutil (da forma como Damasio coloca a questão), pois se refere a um modo de estruturação das experiências sensitivas, perceptivas e cognitivas do ser humano, que não funcionariam segundo uma lógica dual (mente-corpo), mas numa complexa rede de interações, o que não deixa de ser interessante, em termos de ampliação das experimentações corpóreo-subjetivas. 
No entanto, o incômodo persiste e se agrava ao se perceber que o efeito dessa concepção renovada do corpo nos conduz ao recrudescimento do organismo como "realidade" do ser humano, só que agora renovada e ampliada. Ou seja, o sujeito, cuja sede era a alma ou a mente, agora pode ser entrevisto nas redes neuronais e na sua constituição corpórea como um todo. A ampliação perspectiva em relação ao ser humano que daí emerge é inegável. Mas, antes de nos lançarmos a uma crítica ao possível (mal) uso que se venha a fazer de tal ou qual teoria neurofisiológica, devemos atentar, à maneira de Nietzsche (1992, p. 9), para a vontade que a quer. Ou melhor: "o que quer a vontade" que quer ver o sujeito encarnado, que quer uma mente no próprio organismo? Não seria isso uma nova organização, ordenação, só que agora através do corpo, no próprio corpo?

Damásio (1996, p. 276 et seq.) nos fala de uma "paixão pela razão", como um elo de ligação entre razão - sentimentos - corpo:

A razão, da prática à teórica, baseia-se provavelmente nesse impulso natural por meio de um processo que faz lembrar o domínio de uma técnica ou de uma arte. Retirese o impulso, e não é mais possível alcançar essa perícia" (DAMÁSIO, 1996, p.276).

Parece que a razão, ela própria, tenha se tornado mais "flexível", em "rede" etc. E, repita-se, não é que isso seja um problema em si, como se devêssemos retornar a uma configuração anterior - como se acaso tivéssemos para onde retornar.

Outros autores, como Kai Vogeley e Albert Newen (2004), são mais incisivos ao afirmarem a correlação mente-corpo. Em artigo em que discutem o que seria o Eu à luz das neurociências, assim escrevem, ao criticarem o dualismo cartesiano:

A ciência cognitiva moderna rejeita o dualismo [cartesiano]. Ela sustenta que os fenômenos mentais também são, em última instância, nada mais que fenômenos físicos, e que precisamos renunciar à idéia de um Eu não-físico. Em vez disso, pode-se conceber a autoconsciência como uma forma de consciência de especial complexidade, surgida tardiamente ao longo da evolução. [...] No âmbito da pesquisa cerebral, sobretudo a chamada teoria da identidade revelou-se uma fértil base teórica. Ela afirma que os processos mentais são, em princípio, idênticos aos processos neuronais (NEWEN; VOGELEY, 2004, p. 60).

É inegável que esta perspectiva ressalta, nas subjetividades, a sua dimensão corporal inerente. Entretanto, o perigo da manutenção de um mesmo ideal caro ao cartesianismo - uma razão redentora - retorna numa forma corporalizada: é a conservação do sujeito, em sua adequação à unidade corporal. $\mathrm{O}$ que, muitas vezes, parece-nos uma versão high-tech do cartesianismo, pois este havia, através do cogito, erigido um sujeito racional que não conseguia experimentar a desterritorialização sob risco de ruir, de desmoronar de seu castelo de 
areia. ${ }^{16}$ Agora o sujeito é corpo. E, de nossa parte (para nossa época), sente-se novamente o cheiro da interdição. Novos territórios são demarcados e as experimentações minguam em meio à proliferação do mesmo: um corpo saudável e conservado, depurado de suas singularizações, não havendo muito espaço para a vida exercer sua potência de variação "no" corpo.

E, no entanto, não há como, talvez não haja mesmo porque questionar a forma desse corpo redescoberto, redivivo e com status renovado, pois há aí uma espécie de euforia, mesmo que algo incomode, como se este corpo redescoberto, que é freqüentemente convocado à saúde e à conservação, não nos levasse muito longe, não nos potencializasse - tanto que se busca incrementar esta euforia através de substâncias químicas como a cocaína e o ecstasy.

É preciso, mesmo, ir mais a fundo e perguntar sobre as saídas, ou melhor, as linhas de fuga, no sentido em que Deleuze e Guattari (1996[1980]) as entendem como possibilidades de contraposição ao poder, e como forma de organização de um campo social do desejo. Pois, segundo estes autores, "[...] não se trata de cada um fugir 'pessoalmente', mas de fazer fugir, como quando se arrebenta um cano ou um abcesso" (DELEUZE; GUATTARI 1992, p. 30).

Em outros termos, poderíamos nos perguntar: o que temos feito para fazer passar os fluxos? Que artifícios temos inventado? Quais teremos que inventar? Algumas linhas de fuga começam a ser entrevistas. Linhas que partem do corpo, mas que indicam uma outra configuração: processualidades corporais. Pois o corpo "também" é (ou pode ser) a experiência que nos arranca de uma regularidade, que abre um espaço de experimentação sem Eu. Em outras palavras, o corpo como aquele que não sabe fazer promessas. ${ }^{17} \mathrm{O}$ homem (carne-e-espírito) é aquilo que promete; o corpo (espaço intersticial) é aquilo que se des-com-promete, o que esquece. Esquece-se das prescrições, de conservar-se, insiste em brincar nas bordas do sentido: esquecendo-se do dever, o corpo "devém".

Este corpo-devir é necessariamente uma problematização do que temos experimentado como corpo em nossa contemporaneidade. Pois o conceito de devir - que remonta a Heráclito, filósofo pré-socrático - desloca e transformam nossa perspectiva, amiúde ancorada na identidade e na representação, categorias referentes ao mesmo; e nos remete a pensarmos o outro, ou melhor, a alteridade. E se pensarmos o devir em relação ao corpo, é da própria afirmação da impermanência que se trata: afirmação do devir-corpo.

Pois não há ser além do devir, não há o um além do múltiplo; nem o múltiplo, nem o devir são aparências ou ilusões. Mas também não há realidades múltiplas e eternas que seriam, por sua vez, como essências além da aparência. O múltiplo é a manifestação inseparável, a metamorfose essencial, o sintoma constante do único. O múltiplo é a afirmação do um, o devir, a afirmação do ser (DELEUZE, 1976, p. 19). 
$\mathrm{Na}$ verdade, se refletirmos mais atentamente ao que temos vivido na contemporaneidade, é possível diferenciar pelo menos duas séries de corporeidades: há uma série estratificada, cujo corpo-organismo serve à encarnação de um Eu; e há uma outra série, em que o corpo, em processo de construção de um corposem-órgãos $(\mathrm{CsO})$, um corpo-devir, abre-se às experimentações e explode o $\mathrm{Eu}$ do interior de sua imanente fluidez, pois não há corpo: há que produzi-lo.

O corpo-sem-órgãos $(\mathrm{CsO})$, noção criada por Antonin Artaud e utilizada por Deleuze e Guattari (1996[1980]), refere-se de um modo geral a uma ruptura do corpo feito organismo. Deleuze e Guattari escrevem, na esteira de Artaud, que o CsO não se contrapõe aos órgãos, pois a batalha que ele encarna é contra o organismo: "O inimigo é o organismo. O CsO não se opõe aos órgãos, mas a essa organização dos órgãos que se chama organismo" (DELEUZE; GUATTARI, 1996 [1980], p. 21). Como há uma saturação nesse corpo organizado, que barra a passagem dos fluxos, o CsO, enquanto processo, possibilita uma abertura e uma limpeza do corpo, na tentativa de "paciente e momentaneamente desfazer esta organização dos órgãos que se chama organismo" (DELEUZE; GUATTARI, 1996 [1980], p. 23). Enfim, o CsO é o ovo, como superfície de circulação de intensidades:

O ovo é o meio de intensidade pura, o spatium e não a extensio, a intensidade Zero como princípio de produção [...], onde as coisas, os órgãos, se distinguem unicamente por gradientes, migrações, zonas de vizinhança (Deleuze; Guattari, 1996 [1980], p. 27).

Mas isso ainda não nos leva muito além: há um cheiro de maniqueísmo no ar (corpo estratificado X corpo-sem-órgãos), quando, efetivamente, a diferença é mais sutil. Em vez de pensarmos a diferença apenas em termos de natureza, podemos pensá-la em termos de quantidade intensiva "e" diferença qualitativa. E isso nos conduz a um tipo de problemática que se refere ao corpo e à potência de vida. Ou seja, será que ainda é possível buscar no corpo um suporte para a potencialização da vida?

A pergunta, a princípio, parece estúpida, talvez por ser aparentemente tão óbvia. Pois, afinal, vivemos uma contemporaneidade marcadamente biologicista. Não que não tenhamos vivido assim há muito tempo. Isto é, se tomarmos por base as reflexões de Michel Foucault $(1990 ; 1988)$ sobre o biopoder e a biopolítica, a bios, a vida está no cerne das relações de força, desde pelo menos fins do século XVIII. Neste sentido, e seguindo as análises de Foucault, que afirmam que "o corpo é uma realidade bio-política" (Foucault, 2006, p. 80), parece-nos que, além dele ter sido objetivado, agora tem se tornado cada vez mais evidente. De lá para cá (do século XIX ao XX e começo do século XXI), em que a vida ainda ocupa a centralidade das estratégias de poder e saber, a identificação entre a vida e o corpo como sua evidência só fez recrudescer.

Desse modo, não é de se estranhar que nos pareça tão óbvio atualmente que se conserve o corpo na busca pela preservação da vida. E o que se tem é uma popularização - ou mesmo uma banalização - dessa perspectiva biológica atra- 
vés de uma "fisiologia para as massas". Para uma tal constatação basta dar uma olhada em qualquer banca de revistas e verificar a proliferação de publicações de divulgação científica, e a freqüência com que veiculam matérias sobre a fisiologia humana, sobretudo neurofisiologia. Exemplo paradigmágico disso é a revista $V i$ ver Psicologia que, a partir de 2004, passa a ser Viver Mente \& Cérebro (Duetto Editorial, como uma ramificação da Scientific American Brasil), com conteúdo baseado, sobretudo nas neurociências.

Além disso, as revistas semanais, revistas femininas, telejornais etc. trazem, com esclarecedora regularidade, reportagens sobre o corpo humano, como cuidá-lo, novas e velhas doenças, novos tratamentos e "novíssimos" métodos diagnósticos. O corpo, em toda a sua densidade fisiológica, que inevitavelmente passa pela genética, é assunto cotidiano.

Mais que isso, após um longo processo pelo qual o corpo foi constituído como objeto de conhecimento, hoje ele desfruta de uma imagética: é um corpo-imagem. A produção de imagens sobre o corpo - na ciência e na mídia, por exemplo - opera paralelamente em duas direções: se, por um lado, sublinha a obviedade de um corpo como sinônimo de vida; por outro, de certo modo, desencarna este corpo: imagem sem carne.

A evidência que aí se sublinha é a de que a vida estaria inexoravelmente grudada ao corpo. No entanto, o que se observa amiúde é um corpo esvaziado, descarnado. Mas o que seria a carne? Justamente as turbulências que atravessam o que experimentamos como corpo. A carne é o intensivo, que, antes de caracterizar o corpo (como organismo), descaracteriza-o, ou, seguindo Francis Bacon (o pintor), "desfigura-o".

Por isso que se pode afirmar que essa evidência é uma armadilha: como se fosse tão evidente que a vida habitasse o corpo, que não seria necessário produzila. Ou melhor, já que é evidente que a vida é corpo (ligação essencialista entre os termos), é produzindo corpo que se produzirá vida. E é nesse ponto que uma questão superficialmente simples (evidente) ganha uma densidade própria: as políticas do corpo na contemporaneidade.

O corpo que se quer produzir (nossa política hegemônica do corpo) é, antes de tudo, um corpo conservado, que envolve a negação das passagens, das inscrições, dos paradoxos: quer-se a negação da carne. Um corpo liso, limpo, sem marcas. E nessa operação, mesmo que se ganhe em permanência e conservação, perde-se muito em experimentação e em potência.

A forma como se tem sustentado o dispositivo corporal, apesar do aparente entusiasmo em relação às mudanças, assenta-se numa evitação da problemática própria às experimentações. Isto quer dizer que o transformável contemporâneo do corpo não diz respeito ao devir, que traz consigo as forças do acaso, próprias aos efeitos da imprevisibilidade do encontro com a alteridade cambiante do outro; as transformações referem-se, isso sim, a uma melhoria, uma implementação. E, acima de tudo, a um si-mesmo que tende inevitavelmente a se expressar, a se evidenciar, e que encontra geralmente no outro nada mais do que um espectador. 
Essa tendência à evidência encontra sua expressão mais contemporânea nas já citadas neurociências, que investem sobre uma interioridade que nunca fora tão visível, tanto em sua estrutura, quanto, mais recentemente, em seu "movimento" - como, por exemplo, nas tomografias por emissão de pósitrons (TEP) e os "mapeamentos" da atividade cerebral por elas realizados. Mesmo porque o conhecimento que se propõem produzir sobre o funcionamento cerebral nos promete uma compreensão "plena" de nossa subjetividade. Corpo e subjetividade parecem se cruzar no cérebro. Mais ainda: o cérebro, laureado há mais de uma década como o portador da verdade do sujeito, é o principal candidato a materializá-lo, resolvendo, enfim, uma antiga querela do pensamento ocidental. Ou seja, o que fora uma longa discussão filosófica sobre a mente, parece ter encarnado. E o corpo, que já fora negado e vivido como uma prisão, tem assumido uma positividade tal que beira a onipresença.

$\mathrm{Na}$ verdade, algo no homem, sobretudo a partir do século XIX, com o advento da anatomopatologia, aguçou a atenção para o corpo, renovou-a, deulhe outro significado, na forma de uma decifração do sujeito. Este parece ter sido arrancado definitivamente do mundo mental para encarnar uma interioridade corpórea, como se lhe fosse possível habitar um território interior o suficiente para não ser evidente e, portanto, requerer sua decifração; e, ao mesmo tempo, corpóreo o bastante para ser visível, até mesmo palpável. O que temos hoje, via neurociências, é uma estrutura da subjetividade que começa a ser delineada nas inter-relações sinápticas e nos quebra-cabeças de nucleotídeos que compõem o nosso DNA. Isto é, o corpo tem sido envolvido numa rede de significados em que tudo parece levá-lo a se expressar: as células (e seus núcleos), os seus movimentos, as marcas na pele, os hábitos, os comportamentos, as roupas, o que se consome...

E por mais que isso nos convide a um ufanismo desenvolvimentista - o progresso da ciência etc. -, há algo que se estanca no fluxo vital e que se refere à manutenção do sujeito numa interioridade agora corporificada. Ou seja, repõe-se o sujeito em sua interioridade, agora através do corpo. Se antes o corpo, em sua animalidade latente, ameaçava arrastar o homem para as fronteiras da sua humanidade, agora é o corpo que o humaniza, fazendo-o materializa-se.

$\mathrm{O}$ cogito era um exercício, uma conquista frente às adversidades de um senso comum e às tentações da carne sensitiva e freqüentemente "iludida". O cogito era a fagulha de certeza que Descartes vislumbrou em meio às trevas das crenças e opiniões da sua época. Mas esse cogito não se conciliava com o corpo, o que bem nos mostra o dualismo cartesiano.

Agora, visualizamos uma pacificação entre os termos, e o corpo parece oferecer alguma segurança, em tempos tão incertos como os nossos: ele nos assegura de nós mesmos, e nos segura desde dentro. Daí que se tenha que ir além. Uma vez que o cogito, agora, encarnou, cabe-nos testar seus limites, pois, se é aí (encarnação) que está todo seu perigo, também é aí que está nossa maior potência, não no corpo como evidência redundante, mas na carne, isto é, na potência advinda justamente das reverberações em nossa carne, no esfacelamento do sujeito que faz a nossa "carne gritar", tal como as pinturas de Francis Bacon. 


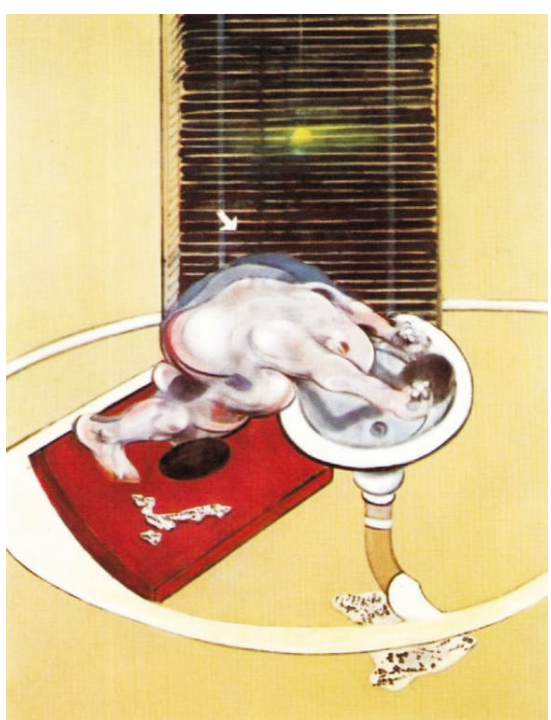

Figura 1: Francis Bacon, Figure at a Washbasin, 1976

Gilles Deleuze, em seu trabalho sobre este pintor (Deleuze, 1981), apresenta-nos uma intensidade deformativa do corpo, ou melhor, matéria intensiva que deforma os contornos corporais. A partir daí, podemos pensar que humanizar o corpo seria lhe impor um certo contorno (humano), na tentativa de acabar com a tensão da matéria intensiva que o deforma. Só que esta tensão não se cala, a carne grita, é sua potência, o seu devir.

Não nos cabe questionar o porquê disso, mas sim experimentarmos o como. Isto é, quais os modos de experimentação dessa força que deforma, e como experimentar sem desmoronamento? Poderíamos experimentar, "através" do corpo, formas de trair o sujeito que aí insiste em se alojar? É-nos possível pensar, atualmente, o corpo abrindo-se ao devir?

Avancemos ainda mais: será que não se poderia pensar o corpo como potência do inumano, uma possibilidade de transposição do humano, ou, usando um termo caro a Nietzsche, experimentações do além-homem? Como se, na sua quase insuportável contradição, essa possibilidade descortinasse uma linha de fuga atroz, cruel, pulsante: na obviedade plácida de que todo corpo é o espaço por excelência do humano, justamente aí decompô-lo, fazendo o corpo buscar o intensivo que escapa aos órgãos (corpo-sem-órgãos), envolvendo os presentes num ritual de espanto, de estranheza, em que o corpo (em sua organização) vai se tornando inumano em sua recomposição intensiva: devir corpo. ${ }^{18}$

Isso nos faz pensar na dança, pois o que há de mais interessante na dança contemporânea são justamente essas tentativas de subverter a obviedade do corpo. A despeito de qualquer virtuosismo, explorar um devir-corpo em dança. Explorar o movimento e, através da dança, compor um corpo que não está dado, que não se evidencia. Tornar audível esse grito da carne em seu atletismo intensivo. E para isso não é necessário gritar literalmente, nem se contorcer obstinadamente; pois é na singeleza das composições, no inusitado dos encontros que a arte nos mostra que há uma vida crua aquém e além de qualquer prévia organização do corpo.

Afinal, entre corpo e pensamento há encontro possível? Na sopa de palavras que inunda o pensamento, que alinhava o corpo, há mais estranhamento. Descompasso, disritmia. E é aí que o corpo começa a jogar e a trair. Atrair. E o pensamento, envolvido pela dança, deixa que se percam as palavras-costura, em proveito do movimento. "O corpo pensa" - conforme nos provocava o subtítulo do FID (Festival Internacional de Dança - Extensão Brasil) em 2003. 
Hubert Godard (2006, p. 76) fala da possibilidade da dança contemporânea em "suprimir essas compartimentações [dos sentidos] que são provocadas pela catástrofe da linguagem, pela história". É que a dança contemporânea nos mostra, enquanto convite à experimentação, um caminho possível para se atravessar a armadilha da evidência do corpo-imagem que nos satura a contemporaneidade. Não é o único caminho, e talvez nem seja o melhor. Mas é um convite muito tentador este que a dança nos apresenta: o de conectar arte e vida para além de qualquer conservação. A impressão que se tem é que a vida se alarga.

O corpo, no movimento dançado, atualiza a carne, em sua dor e em sua alegria e festa. Abre espaço, inclusive para uma relação corpo-pensamento em que o sentido inventa palavras, empurrando-as garganta afora. A voz, então, é um ato do corpo em movimento, que forma fluxos de interiorização e exteriorização. É aí que se vislumbra a composição de um espaço público para o corpo, que não seu mero espetáculo. É a afirmação do corpo, da voz e da vida pública.

Enfim, a dança, como potência de criação em seus exercícios disruptivos, abre em leque o corpo, tornando-se um campo de possibilidades ao exercício de novas corporeidades: a despeito de qualquer herança, é criação de presente em ato. Confere uma possibilidade de se criar uma voz possível através do ${ }^{a}$ movimento. Para além de uma suposta geração, mas sem negar sua época (seu presente), o movimento do corpo-em-dança é uma modalidade de se experimentar a vida em sua potência de invenção e resistência.

\section{Notas}

${ }^{1} \mathrm{O}$ conceito de devir abordado no decorrer do texto, refere-se à discussão filosófica, ancorada no pensamento de Heráclito de Éfeso (filósofo pré-socrático, séc. V a.C.), desenvolvida posteriormente por Friedrich Nietzsche (segunda metade do séc. XIX), e mais contemporaneamente por Gilles Deleuze (em seus trabalhos a partir dos anos 1960). Cf. Deleuze (2003; 1976); Nietzsche (1995); Souza (1996 apud HERÁCLITO).

${ }^{2}$ As menções à dança contemporânea, que aparecem no decorrer deste trabalho, referem-se, de um modo geral, ao que há de experimentação nesta modalidade de dança, no sentido de quebra com o virtuosismo e a espetacularização. De forma mais específica, tomam-se como referência as experimentações a partir da técnica denominada Contato Improvisação (contact impovisation, ou CI), desenvolvida por Steve Paxton e colaboradores (cf. BANES, 1987, p. 71 et seq.), nos EUA a partir dos anos 1970, em que o movimento dançado se dá a partir do contato com o corpo do outro, com o solo e com todo e qualquer elemento com o qual nos relacionamos

${ }^{3}$ Mesmo que haja muitas proximidades entre os acontecimentos que ocorreram, nesse período, no Brasil e em outros países da América Latina, e mesmo na Europa e na América do Norte, o que se está focalizando aqui é o caso brasileiro, com a especificidade de sua contracultura, e a dureza de sua ditadura militar.

${ }^{4} \mathrm{O}$ conceito corpo vibrátil foi elaborado por Suely Rolnik (2004a; 2006), e nos remete a um modo de subjetivação que configura o mundo à maneira como este se apresenta ao corpo, na forma de vibração e contágio. Esse modo implica, sobretudo, uma vulnerabilidade ao mundo.

${ }^{5}$ Há que se ressaltar que a denominação de "desbunde" e "desbundados" tinha um cunho marcadamente pejorativo. Como exemplo paradigmático, pegue-se a quinta acepção da palavra no Dicionário Houaiss: "5. adoção de comportamento libertino e estilo de vida alternativo. Ex.: o d. da geração de 1960."

${ }^{6}$ Cabe uma observação: a prática da guerrilha não é uma tentativa de transformação; mas uma violenta investida contra um terrorismo de Estado, com vistas a retomar um processo de transformação desencadeado nos anos 60, e encarnado no governo, posteriormente deposto, de João Goulart. Na verdade, o fluxo de transformação (macropolítica) fora estancado pela ditadura 
militar, e o ideário da guerrilha pode ser lido como uma forma de tentar restabelecer esse fluxo.

${ }^{7}$ Suely Rolnik, ao discutir a dissociação entre as potências de criação e as de resistência, resumida e precisamente assim situa a política: "o exercício da polêmica acerca das configurações da vida em sociedade, seus recortes e as regras que as sustentam" (ROLNIK, 2004b, p. 30).

${ }^{8}$ Não é que não exista um "culto ao corpo" anterior aos anos 80 , mas, no Brasil, esse período é marcado por uma interiorização da experiência deste corpo, no que diz respeito à sua dimensão sensível, e a uma exteriorização exibicionista como forma de encarná-la. Isso trará importantes - e pungentes - conseqüências à produção de subjetividades que se sucederá.

${ }^{9}$ Sobre o dever de ser feliz, ver o sucinto, mas provocador texto de Denise de Sant'Anna, "Sutilizas e Misérias", in.: SANT'ANNA, 2001, p. 121 et seq.

${ }^{10}$ Sobre a cultura narcisista do corpo, com sua aparente busca pelo prazer (um suposto hedonismo) e a relação disso com uma nova distribuição das coações (disciplinamento), ver o esclarecedor texto de Jean-Jacques Courtine, "Os Stakhanovistas do Narcisismo: body-building e puritanismo ostentatório na cultura americana do corpo", in.: SANT'ANNA, 2005, p. 82 et seq.

${ }^{11}$ A noção de essência aqui tratada refere-se à teoria espinosista das substâncias, encontrada na Ética, e discutida por Deleuze em seu livro sobre Espinosa (Deleuze, 2002), no glossário elaborado por aquele autor. Segundo esta teoria, essência refere-se a uma reciprocidade, uma vez que uma essência se configura como tal numa relação recíproca. Deste modo, antes de nos remeter ao que comumente denominamos - de forma crítica, inclusive - como um essencialismo, esta teoria, vista desta perspectiva, remete-nos às singularidades, pois as substâncias são caracterizadas (sua essência) por seu grau de potência próprio, ou melhor, por seus graus de intensidade ou quantidades intensivas. Cf. DELEUZE, 2002, p. 79 et seq.; ESPINOSA, 1991, p. 141 et seq.

${ }^{12}$ A discussão acerca do corpo como dispositivo foi realizada, anteriormente, alhures (cf. SILVA, 2007). No entanto, para o que nos interessa neste trabalho, cabe ressaltar que o corpo é entendido como dispositivo na medida em que, seguindo a elaboração teórica de Michel Foucault (2006), compreende tanto uma formação reticular de elementos heterogêneos (discursos, enunciados científicos, práticas etc.), quanto uma dimensão estratégica - no sentido de responder a uma urgência. Cf. FOUCAULT, 2006, p. 243 et seq.

${ }^{13}$ Para as elaborações que se seguem, referentes à forma-Deus, forma-Homem e super-homem, utilizamos o excelente trabalho de Gilles Deleuze sobre o pensamento de Foucault. Cf. DELEUZE, 2005 , p. 132 et seq.

${ }^{14}$ Jurandir Freire Costa (2004, p.203), em seu livro sobre corpo e consumismo, fala de um "novo narcisismo corporal [referindo-se ao que denomina] cultura somática [e que engendra um] ideal do sujeito sentimental". Na acepção deste autor, estamos vivendo numa época em que se pode falar em "cultura do corpo, [que aponta] para o fato de o corpo ter se tornado um referente privilegiado para a construção das identidades pessoais" (COSTA, 2004, p.203). É neste sentido, o de ter o corpo assumido o papel de referente identitário, que se fala aqui da emergência de um eu-corpo na contemporaneidade.

${ }^{15}$ Cf., por exemplo: VARELA, Francisco; THOMPSON, Evan; ROSCH, Eleanor. A Mente Incorporada: Ciências cognitivas e experiência humana. Porto Alegre: Artmed, 2003. Cf. também as pesquisas de Hubert Godard, especificamente aquelas voltadas ao corpo na dança, por exemplo: GODARD, Hubert. Gesto e percepção. Tradução Silvia Soter. Lições de dança, Rio de Janeiro, n. 2, p. 11-35, 2001; e a entrevista de Hubert Godard a Suely Rolnik sobre o trabalho de Lygia Clark: "Olhar Cego: entrevista com Hubert Godard" (GODARD, 2006).

${ }^{16}$ Michel Foucault, em algumas das mais belas páginas de seu monumental estudo sobre a loucura, mostra-nos como Descartes se viu às voltas com a desrazão, tendo que contorná-la, elidi-la, sob pena de, desde o fundamento, ver comprometido seu edifício racional. Cf. FOUCAULT, 1991.

${ }^{17}$ Nietzsche (1998[1887], p. 47) nos fala do homem como "um animal que pode fazer promessas". A reflexão aqui proposta segue a linha do esquecimento ativo nietzschiano, que é a antítese das promessas.

${ }^{18}$ Não seria essa a concepção de Artaud para o seu teatro da crueldade? A crueldade do teatro seria justamente trazer o "cru" da vida para o palco, envolvendo os presentes num ritual de ampliação da vida, de intensificação etc. (cf. ARTAUD, 1993). ${ }^{1}$ 


\section{REFERÊNCIAS}

ARTAUD, A. O Teatro e seu Duplo (1964). Tradução Teixeira Coelho. São Paulo: Martins Fontes, 1993.

A DÉCADA de cada um: depois da frustração dos anos 60, o homem da década de 70 tornou-se prático, cultivou o espírito e investiu no corpo... Veja: Os anos 70, São Paulo,ano 12 n. 590, p. 56-70, 26 dez. 1979. Seção Comportamento. Edição Especial.

BACON, F. Figure at a Washbasin. 1976. Oil on canvas. $198 \times 147.5 \mathrm{~cm}$

BANES, S. Terpsichore in Sneakers: post-modern dance. Hanover: Wesleyan University, 1987.

COSTA, J. F. O Vestígio e a Aura: corpo e consumismo na moral do espetáculo. Rio de Janeiro: Garamond, 2004.

DAMASIO, A. R. O Erro de Descartes: emoção, razão e o cérebro humano. Tradução Dora Vicente; Georgina Segurado. São Paulo: Cia. das Letras, 1996.

DELEUZE, G. Foucault. Tradução Claudia Sant'Anna Martins. São Paulo: Brasiliense, 2005.

. Lógica do Sentido. Tradução Luiz R. S. Fortes. 4. ed. São Paulo: Perspectiva, 2003.

. Espinosa: filosofia prática. Tradução Daniel Lins e Fabien Lins. São Paulo: Escuta, 2002.

. Francis Bacon: logique de la sensation. Paris: Difféfence, 1981.

.Nietzsche e a Filosofia. Tradução Edmundo F. Dias; Ruth J. Dias. Rio de Janeiro: Rio, 1976.

DELEUZE, G.; GUATTARI, F. Mil Platôs: capitalismo e esquizofrenia (1980). Tradução Aurélio Guerra Neto et. al. São Paulo, 1996.

. Entrevista sobre o Anti-Édipo. In.: DELEUZE, G. Conversações (19721990). Tradução Peter P. Pelbart. São Paulo, 1992.

DESBUNDE. In: HOUAISS, A. (Ed.). Dicionário Eletrônico Houaiss da Língua Portuguesa. São Paulo: Objetiva, 2001. CD-ROM. 
DIAS, L. Anos 70: enquanto corria a barca. São Paulo: SENAC, 2003.

ESPINOSA, B. Pensamentos Metafísicos; Tratado da Correção do Intelecto; Ética (1677). 5. ed. São Paulo: Nova Cultural, 1991. Coleção Os Pensadores.

FOUCAULT, M. História da sexualidade: a vontade de saber. Tradução de Maria Tereza da C. Albuquerque e J. A. G. Albuquerque. 10. ed. Rio de Janeiro: Graal, 1988. v.1.

. História da Sexualidade: o uso dos prazeres. Tradução de Maria T. da C. Albuquerque e J. A. G. Albuquerque. 6.ed. Rio de Janeiro: Graal, 1990. v. 2.

. História da Loucura na Idade Clássica. 3. ed. São Paulo: Perspectiva, 1991.

. As palavras e as coisas: uma arqueologia das ciências humanas. Tradução

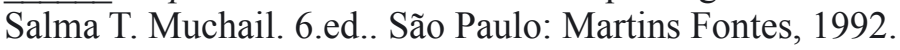

. Microfisica do Poder. Tradução Roberto Machado. 22. ed. Rio de Janeiro: Graal, 2006.

GODARD, H. Gesto e percepção. In: . Lições de dança, Tradução Silvia Soter. Rio de Janeiro, n. 2, 2001, p. 11-35.

.Olhar Cego: entrevista com Hubert Godard, por Suely Rolnik. In:

. Lygia Clark: da obra ao acontecimento. São Paulo: Pinacoteca do Estado, 2006. p. 73-79.

GUARNACCIA, M. Provos: Amsterdam e o nascimento da contracultura. Tradução Leila de Souza Mendes. São Paulo: Conrad, 2001.

GUATTARI, F.; ROLNIK, S. Micropolítica: cartografias do desejo. 7. ed. Petrópolis: Vozes, 2005.

LAPOUJADE, D. O corpo que não agüenta mais. In: LINS, D.; GADELHA, S. (Org.). Nietzsche e Deleuze: que pode o corpo. Rio de Janeiro; Fortaleza: Relume Dumará, 2002. p. 81-90.

NEWEN, A.; VOGELEY, K. O que é Pensar. Revista Viver Mente \& Cérebro, São Paulo, ano 23, n. 140, p. 58-65, set. 2004.

NIETZSCHE, F. W. Genealogia da Moral: uma polêmica (1887). Tradução, posfácio e notas: Paulo César de Souza. São Paulo: Cia. das Letras, 1998. 
NIETZSCHE, F. W. A filosofia na idade trágica dos gregos. Lisboa: 70, 1995.

. Além do Bem e do Mal: prelúdio a uma filosofia do futuro (1885). 2. ed. Tradução, posfácio e notas: Paulo César de Souza. São Paulo: Cia. das Letras, 1992.

ROLNIK, S. Cartografia sentimental: transformações cotemporâneas do desejo. Porto Alegre: Sulina, 2006.

. "Fale com ele" ou como tratar o corpo vibrátil em coma. In: FONSECA, T. G.; ENGELMAN, S. (Org.). Corpo, arte e clínica. Porto Alegre: UFRGS, 2004a. p. 33-45.

ROLNIK, S. L'alterité à ciel ouvert: le laboratoire poético-politique. Multitudes: revue politique, artistique, philosophique, Paris, p. 25-38, winter $2004 \mathrm{~b}$.

SANT'ANNA, D. B. de. Horizontes do Corpo. In: BUENO, M. L.; CASTRO, A. L. (Org.). Corpo Território da Cultura. São Paulo: AnnaBlume, 2005. p. 119134.

. Corpos de passagem: ensaios sobre a subjetividade contemporânea. São Paulo: Estação Liberdade, 2001.

SILVA, J. S. Movimento corporal e processos de subjetivação: um olhar através da dança. In: SOUZA, O. M. M. C.; SOUBBOTNIK, M. A. (Org.). O Corpo e Suas Fic(xa)ções. Vitória: PPGL/MEL, 2007. p. 184-192.

SOUZA, J. C. Heráclito de Éfeso. In: SOUZA, J. C. et al. (Org.). Os PréSocráticos: fragmentos, doxografia e comentários. São Paulo: Nova Cultural, 1996. p. 81-116. Coleção Os Pensadores.

VARELA, F.; THOMPSON, E.; ROSCH, E. A Mente Incorporada: Ciências cognitivas e experiência humana. Porto Alegre: Artmed, 2003.

Recebido em: maio de 2009 Aceito em: agosto de 2009 